\title{
Dynamic Recrystallization and Dynamic Precipitation Behaviors of a 17Ni-0.2C Martensite Steel Studied by In Situ Neutron Diffraction
}

\author{
Pingguang $\mathrm{XU},{ }^{1)}$ Yo TOMOTA ${ }^{1)}$ and Edward C. OLIVER ${ }^{21}$ \\ 1) Graduate School of Science and Engineering, Ibaraki University, Hitachi, Ibaraki 316-8511 Japan. \\ 2) ISIS Facility, Science and Technology Facilities Council, Rutherford Appleton Laboratory, Harwell Science and Innovation \\ Campus, Didcot OX11 00X United Kingdom.
}

(Received on April 23, 2008; accepted on June 23, 2008)

\begin{abstract}
The austenite precipitation and dynamic recrystallization behaviors of $17 \mathrm{Ni}-0.2 \mathrm{C}$ martensite steel during isothermal tempering at $500^{\circ} \mathrm{C}$ followed by isothermal warm compression at $8.3 \times 10^{-4} / \mathrm{s}$ were investigated in situ using neutron diffraction. The Rietveld analysis of Time-Of-Flight neutron diffraction profiles revealed that the austenite amount increased by about $1.5 \%$ during 10 min isothermal holding while the warm compression at $500^{\circ} \mathrm{C}$ accelerated the austenite precipitation. Splitting of the austenite (111) peak occurred and then disappeared during warm compression. Based on integrated intensities obtained by single peak fitting of neutron spectra, it was found from the axial neutron spectra that the ferrite (110) peak intensity rapidly decreased and the ferrite (200) and (211) peak intensities slowly increased during warm compression; the occurrence of dynamic recrystallization led to an evident deviation from this trend. The comparison between lattice strains and texture indexes of austenite and ferrite suggested that the austenite was harder than the ferrite at $500^{\circ} \mathrm{C}$. Thus, heterogeneous deformation occurred in the ferrite, leading to accelerated dynamic recrystallization.
\end{abstract}

KEY WORDS: neutron diffraction; warm deformation; dynamic recrystallization; dynamic precipitation; martensite; austenite; texture index.

\section{Introduction}

Ultrafine grained microstructures have been achieved by either deformation induced phase transformation (DIPT) ${ }^{1)}$ or dynamic recrystallization (DRX). ${ }^{2-5)}$ Recent researches have reported that large strain and a high Zener-Hollomon value may be unnecessary in order to obtain ultrafine grained microstructures if the martensite initial microstructure is employed during annealing after cold working or during warm deformation. ${ }^{6-10)}$ It has been speculated that the high dislocation density of martensite, the strong interaction between carbon atoms and dislocations and the fine substructure of martensite can promote the accumulation of stored energy during warm deformation, and hence accelerate the occurrence of dynamic recrystallization.

Ultrafine grained ferrite or ferrite-cementite steels with $<1.0 \mu \mathrm{m}$ ferrite grain size possess a good balance between strength and toughness. However, their low uniform elongation restricts their potential applications for automobile bodies and frames. ${ }^{11,12)}$ In recent years, ultrafine grained ferrite/austenite duplex microstructures have attracted more and more attention because the transformation of austenite to martensite during straining results in a rapid work-hardening which prevents necking (i.e. transformation induced plasticity, TRIP). It has been reported that such ultrafine grained microstructures can be obtained in various steels by static recrystallization through annealing after cold working or by dynamic recrystallization through warm deformation at a lower temperature in the $\alpha+\gamma$ region. ${ }^{6,13-17)} \mathrm{Mi}-$ crostructural observation of warm compressed specimens with different amounts of pre-existing austenite has shown that a fully recrystallized microstructure can be obtained in a $17 \mathrm{Ni}-0.2 \mathrm{C}$ martensite steel at a small strain $(\varepsilon \leq 0.6)$ and that the existence of austenite plays an important role in accelerating the dynamic recrystallization. ${ }^{17)}$ However, no in situ crystallographic data have been published to characterize the dynamic recrystallization behavior quantitatively and further to investigate the effect of the second phase particles on dynamic recrystallization.

Neutron diffraction has been applied as a powerful tool to investigate the microstructure evolutions of bulk materials during tensile/compressive deformation, heating/cooling and under other specific environmental conditions. ${ }^{18-23)} \mathrm{Re}-$ cently, Time- $\underline{\text { Of-Flight }}$ (TOF) $(h k l)$ multiple reflection spectra obtained by neutron diffraction have been analyzed to evaluate the crystallographic textures during forward and reverse diffusional phase transformations ${ }^{24)}$ and the preferred orientations of ferrite and austenite in a $0.2 \mathrm{C}-2 \mathrm{Mn}$ steel before and after hot compression. ${ }^{25,26)}$ In this paper, the dynamic recrystallization behavior of ferrite and the dy- 
namic precipitation behavior of austenite have been investigated in situ using TOF neutron diffraction during warm compression of $17 \mathrm{Ni}-0.2 \mathrm{C}$ steel.

\section{Experimental Procedures}

The $17.2 \mathrm{Ni}-0.22 \mathrm{C}$ (mass $\%$ ) steel was induction-melted, forged at $1100-900^{\circ} \mathrm{C}$ to $15 \times 15 \mathrm{~mm}$ steel bar and then solution-treated at $1100^{\circ} \mathrm{C}$ for $1.8 \mathrm{ks}$ followed by water quenching. According to the results of dilatometry at a rate of $5.0^{\circ} \mathrm{C} / \mathrm{s}$, the austenite and martensite transformation starting temperatures were $570^{\circ} \mathrm{C}$ upon heating and $125^{\circ} \mathrm{C}$ upon cooling, respectively. Since the warm deformation at a temperature just below the austenite transformation starting temperature accelerated the austenite transformation significantly, a little low temperature $\left(500^{\circ} \mathrm{C}\right)$ was selected in this study in order to investigate the dynamic recrystallization of ferrite. Here, $60 \mathrm{~min}$ pre-tempering treatment at $500^{\circ} \mathrm{C}$ was carried out to obtain about $18 \mathrm{vol} \%$ austenite ${ }^{17)}$ in the initial microstructure. Cylinder specimens with $8 \mathrm{~mm}$ diameter and $20 \mathrm{~mm}$ length were prepared by spark cutting and surface grinding.

TOF neutron diffraction experiments were carried out using the ENGIN-X neutron diffractometer at ISIS, STFC Rutherford Appleton Laboratory, as shown in Fig. 1. The neutron diffraction spectra were measured by two diffraction detector banks in the axial and the radial directions which were centered on horizontal diffraction angles of $\pm 90^{\circ}$ to the incident beam and spanned an angular range of $32^{\circ}$ in the horizontal direction and $42^{\circ}$ in the vertical direction. A $100 \mathrm{kN}$ hydraulic loading rig attached with a radiant furnace with a control error of $\pm 1^{\circ} \mathrm{C}$ was employed to realize thermomechanically controlled process (TMCP). A high-temperature extensometer was employed to monitor the change in strain during warm compression. The sampling volume of columnar specimens for the neutron diffraction was about $80 \mathrm{~mm}^{3}$.

Figure 2 illustrates the temperature history during neutron diffraction schematically. The neutron diffraction spectra obtained from the $60 \mathrm{~min}$ pre-tempered specimen with martensite-austenite duplex microstructure were collected at room temperature and $100^{\circ} \mathrm{C}$ for $10 \mathrm{~min}$ separately, in order to obtain information about the initial microstructure and compare it with that obtained by electron backscattering diffraction (EBSD). ${ }^{17)}$ Then the specimen was heated up to $500^{\circ} \mathrm{C}$ and each neutron diffraction spectrum during the isothermal holding was collected for $1 \mathrm{~min}$ to investigate the effect of the tempering process on the microstructure evolution. After $10 \mathrm{~min}$ isothermal holding at $500^{\circ} \mathrm{C}$, the specimen was compressed at a strain rate of $8.3 \times 10^{-4} \mathrm{~s}^{-1}$ and the neutron diffraction spectra were measured at $500^{\circ} \mathrm{C}$. The neutron spectra collected with a short acquisition period of $1 \mathrm{~min}$ were of low signal-noise ratio, and therefore in order to decrease the experimental error, each spectrum was summed with the consecutive one for the purpose of Rietveld refinement.

Considering the fact that it was difficult to distinguish the diffraction peaks of ferrite and martensite in the neutron spectra, the tempered/deformed martensite and the recrystallized ferrite during warm compression were simply designated as the ferrite matrix in this paper. The austenite vol-
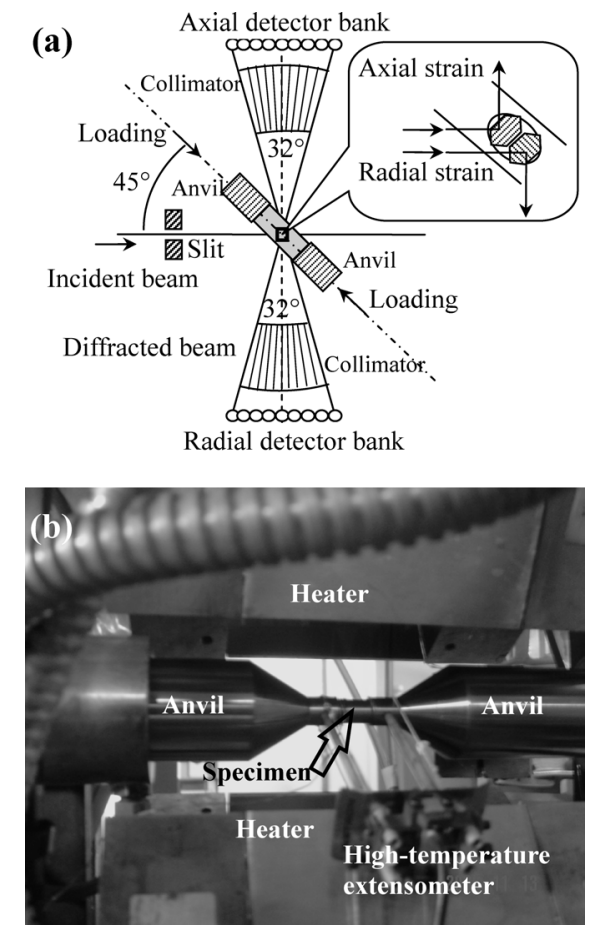

Fig. 1. Schematic plan view of the ENGIN-X neutron diffractometer (a) and the hydraulic loading rig attached with a radiant furnace and a high-temperature extensometer (b).

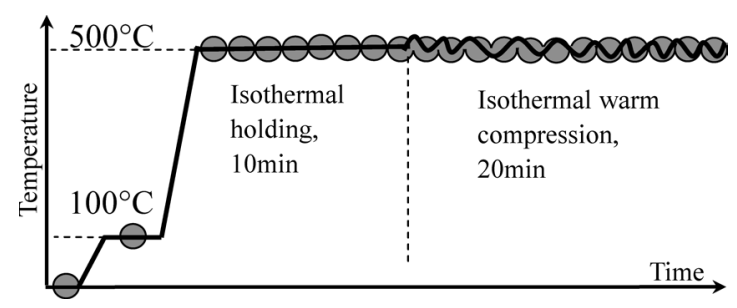

Fig. 2. Schematic illustration of temperature history and deformation process of the steel investigated during in situ neutron diffraction.

ume fraction was determined by Rietveld refinement using the General Structure Analysis System (GSAS) software package, ${ }^{27)}$ taking all diffraction peaks measured into consideration. The texture indexes ${ }^{28)}$ of warm deformed austenite and ferrite were evaluated by the spherical harmonic preferential orientation fitting with an assumption of cylindrical sample symmetry, and the series was truncated at a maximum expansion order of $l_{\max }=6$. Single peak fitting with the third TOF profile function ${ }^{27)}$ was employed to obtain the integrated intensities and the lattice spacings of $(h k l)$ peaks. The preferred orientations and lattice strains of ferrite and austenite were also analyzed by these integrated intensities and lattice spacings, respectively.

\section{Results and Discussion}

\subsection{Microstructure Evolution during Isothermal Holding}

Figure 3 gives an example of the axial neutron spectrum obtained at room temperature and the corresponding $\mathrm{Ri}$ etveld refinement result where the small residual error reveals that the profile fitting quality is good enough. The austenite amount is about $21.0 \pm 0.3 \%$, a little higher than 


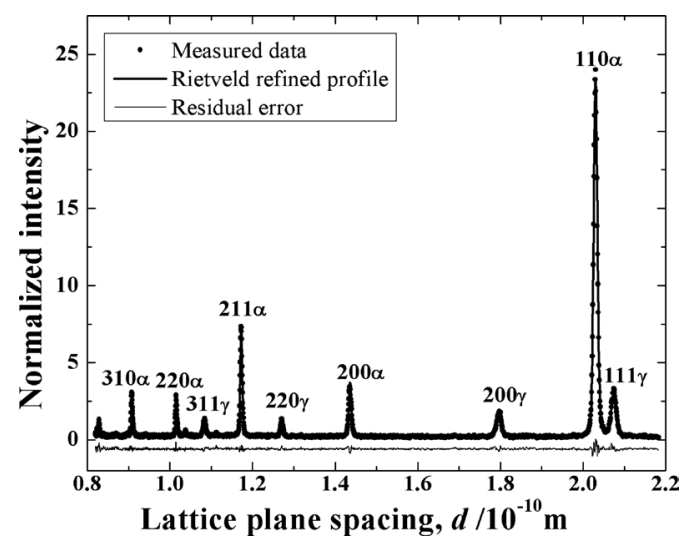

Fig. 3. An example of the neutron diffraction spectrum and Rietveld refinement result using the General Structure Analysis System (GSAS) software, taking all diffraction peaks measured into consideration.

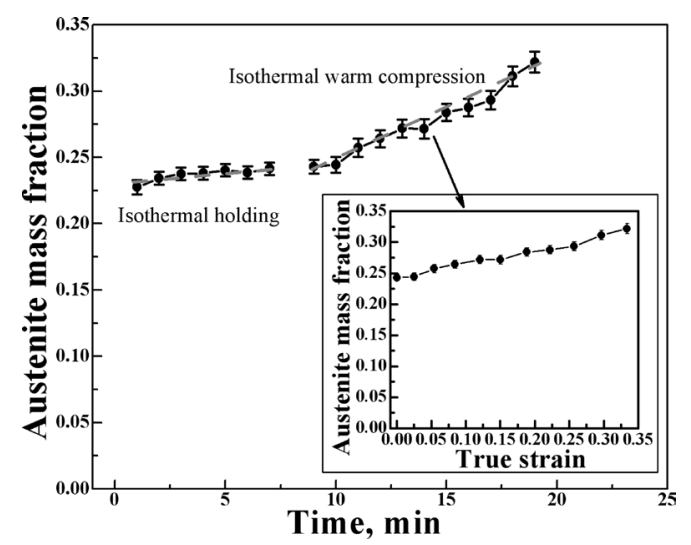

Fig. 4. Change in austenite fraction during pre-tempering and warm compression, where the inserted figure plots the variation against the true strain for the hot deformation stage.

that measured by EBSD technique for an electrochemically polished sample (about 18\%), which is possibly related to the weak stability of austenite, i.e. martensite transformation near surface. ${ }^{29)}$ In addition, no increase in austenite amount can be found during isothermal holding at $100^{\circ} \mathrm{C}$.

Figure 4 shows the change in austenite mass fraction during isothermal holding at $500^{\circ} \mathrm{C}$. The austenite amount increases slowly and results in about a $1.5 \%$ increment after $10 \mathrm{~min}$ holding. This precipitation speed is consistent with that estimated by the microstructure observation where the austenite amount increases from $9.5 \%$ before tempering to about $18 \%$ after $60 \mathrm{~min}$ tempering at $500^{\circ} \mathrm{C} .{ }^{17)}$ These results suggest that the neutron diffraction technique is convincing and suitable to characterize the austenite precipitation during isothermal holding.

\subsection{Change in Austenite Diffraction Spectra during Warm Compression}

Figure 5 shows the stress-strain curve obtained with a high-temperature extensometer during warm compression, where the gray solid circle means the start of neutron profile acquisition. The flow stress approaches the maximum value at a true strain about $\varepsilon=0.13$, and then gradually decreases. Accordingly, the stress-strain curve is divided into two parts: (1) Region I, work hardening; (2) Region II,

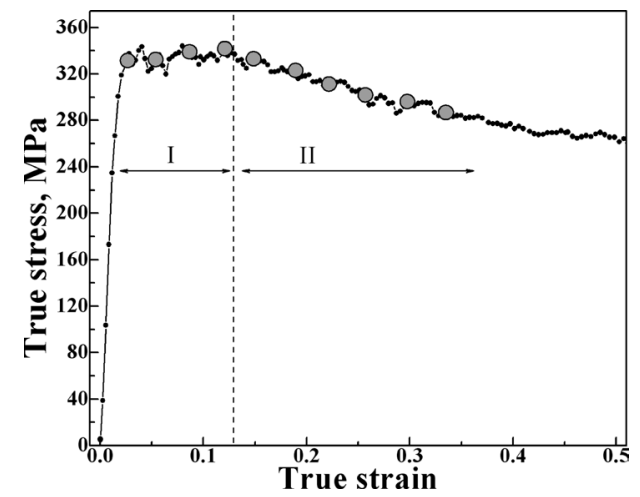

Fig. 5. True stress-true strain curve obtained during warm compression, where gray solid circles correspond to different in situ neutron diffraction spectra and Regions I and II are designated as the work hardening region and the work softening region, respectively.
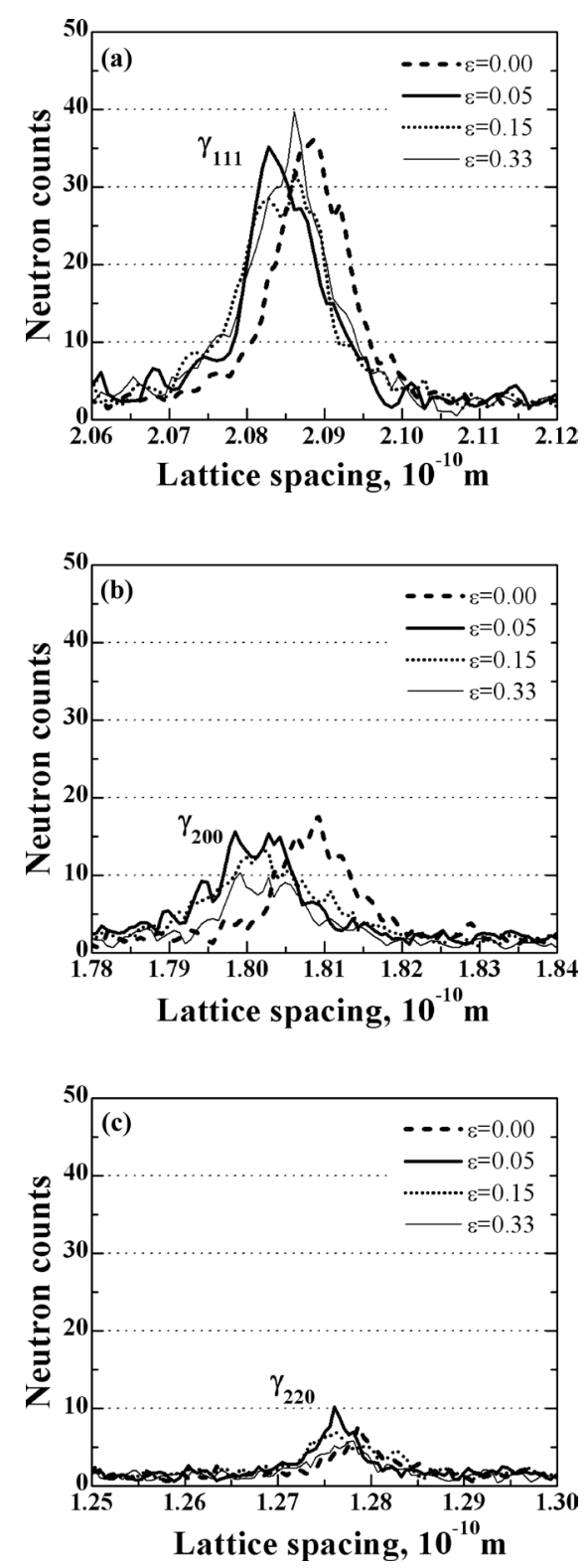

Fig. 6. Comparison of austenite axial diffraction peaks of the $17 \mathrm{Ni}-0.2 \mathrm{C}$ steel at different compressive strains: (a) austenite (111) peak; (b) austenite (200) peak; (c) austenite (220) peak. 
work softening. Figure 4 shows the austenite amount increases gradually with increasing compressive strain, i.e. from $24 \%$ at $\varepsilon=0.0$ to $32 \%$ at $\varepsilon=0.33$. Compared with the isothermal holding, it is found that the isothermal compression accelerates the austenite precipitation.

Figure 6 compares the austenite axial diffraction peaks obtained at different loading steps (see Fig. 5) during the warm compression at $500^{\circ} \mathrm{C}$. Though the austenite (111) peak intensity at $\varepsilon=0.05$ has almost equal intensity and breadth to that at $\varepsilon=0.0$, the (111) lattice plane spacing at $\varepsilon=0.05\left(d_{111}=0.208428 \pm 0.000013 \mathrm{~nm}\right)$ is smaller than that at $\varepsilon=0.0\left(d_{111}^{0}=0.208826 \pm 0.000007 \mathrm{~nm}\right)$. In other words, the lattice strain of austenite, $\varepsilon_{111}=\left(d_{111}-d_{111}^{0}\right) / d_{111}^{0}$, is about $-1906 \times 10^{-6}$, which is comparable with the elastic strain of the specimen estimated by $\varepsilon=\sigma / E=-1781 \times 10^{-6}$ where the external stress $\sigma$ is about $329.5 \mathrm{MPa}$. Here the high-temperature Young's modulus $E$ is taken as $185 \mathrm{GPa}^{30}$ ) That is to say, the $(h k l)$ peak shifts of austenite related to the lattice strain are mostly due to the external stress.

As the true strain increases to 0.15 , the external stress increases only by a little amount (see Fig. 5), so that the amount of further peak shift is very limited (Fig. 7). After this stage, the decreasing external stress with increasing true strain leads to a minor peak shift in the opposite sense.
On the other hand, the austenite (111) peak at $\varepsilon=0.15$ splits into two peaks with lower peak intensities (see Fig. 7(c)). However, this peak splitting gradually disappears by $\varepsilon=0.33$, by which stage there is again a single peak with a higher intensity. Considering the peak intensities of such neutron spectra were not strong, the third TOF profile function $^{27)}$ was employed to fit the austenite (111) peaks (see Figs. 7(b), 7(d), 7(f)). The splitting of austenite (111) peak suggests that newly precipitated austenite possesses different carbon and nickel contents from those of the pre-existing austenite. Then, the chemical composition of austenite gradually becomes uniform with increasing compressive strain.

In order to discuss the austenite evolution during warm compression, it is useful to investigate the change in integrated intensities of the (111), (200) and (220) diffraction peaks as determined by single peak fitting. Figure 8 shows the changes in integrated intensity measured in the axial and the radial directions with increasing of compressive true strain.

At the beginning of warm compression $(\varepsilon<\sim 0.07$, Region Ia), the integrated intensity of the austenite (111) peak decreases and that of the (200) peak increases in the axial direction (Fig. 8(a)) while the austenite (111) peak becomes
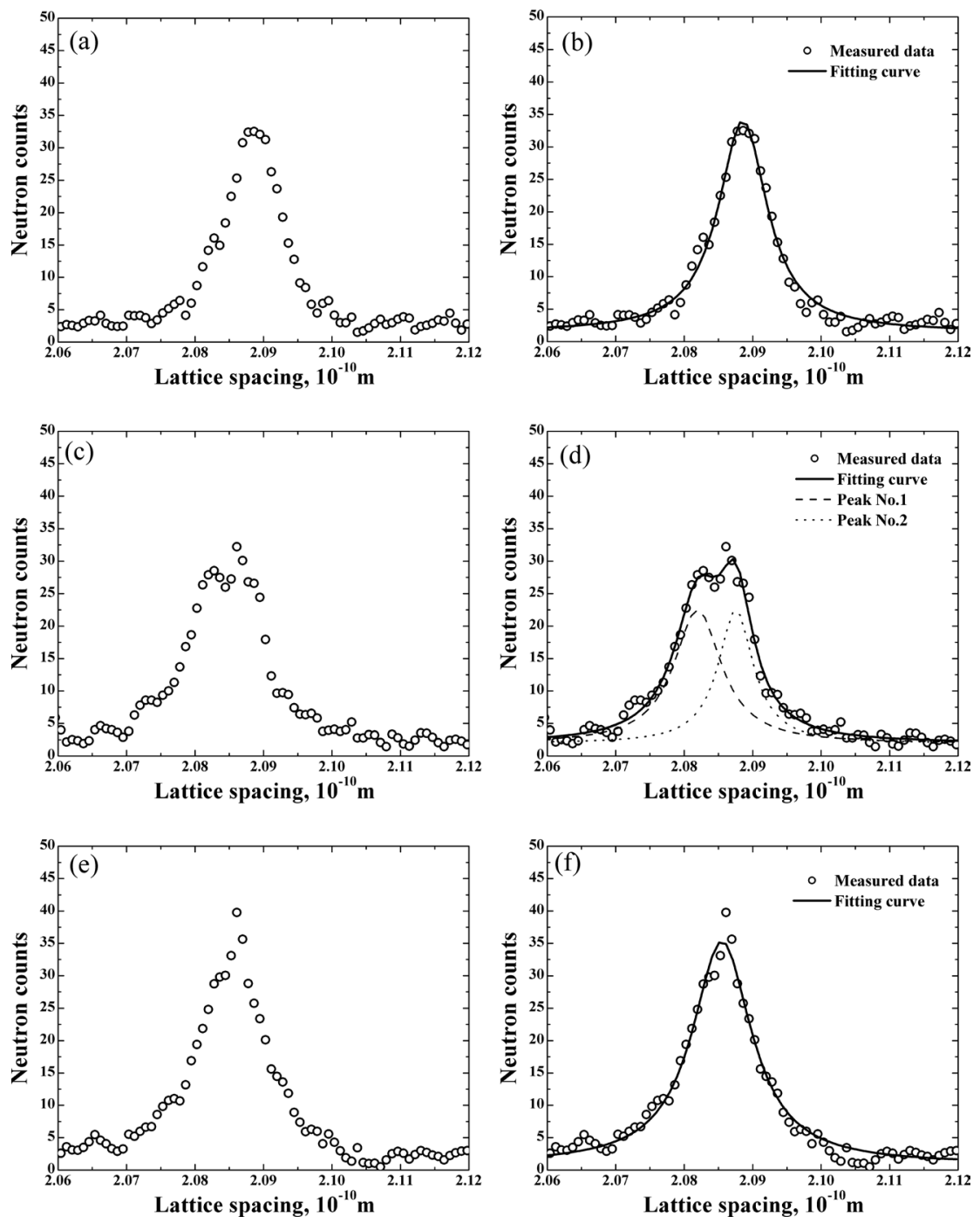

Fig. 7. Austenite (111) peaks and fitting results: (a,b) non-splitting, $\varepsilon=0.0$; (c, d) peak splitting at $\varepsilon=0.15$; (e, f) disappearance of peak splitting at $\varepsilon=0.33$. 

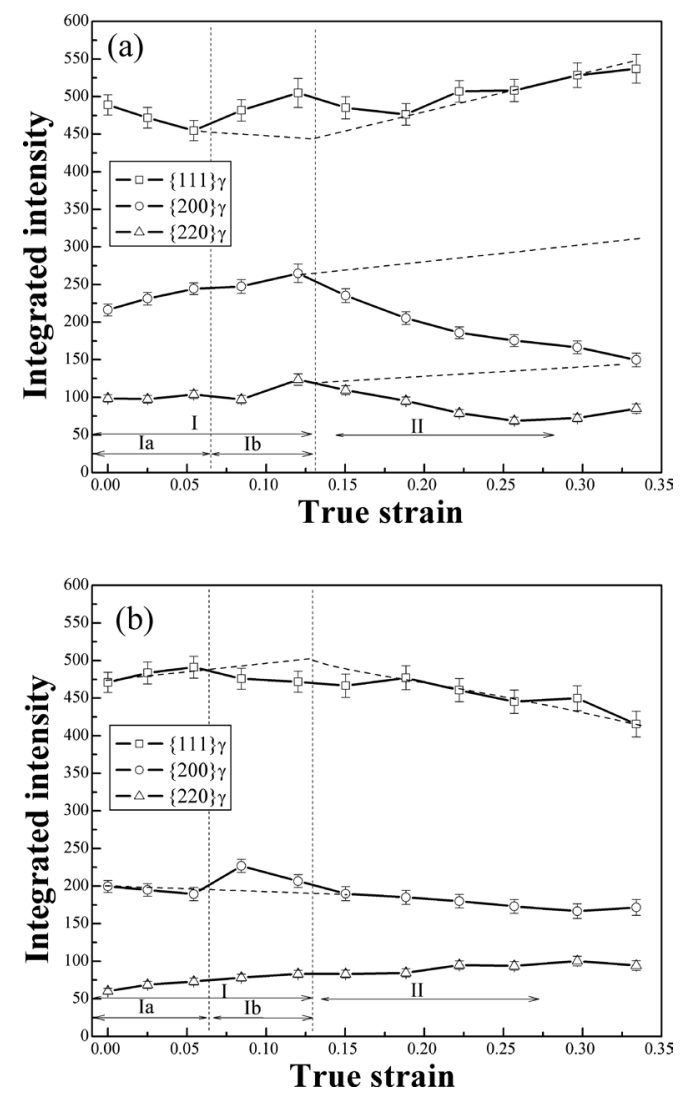

Fig. 8. Change in integrated intensity of austenite in $17 \mathrm{Ni}-0.2 \mathrm{C}$ steel during warm compression: (a) obtained from the axial neutron spectra; (b) obtained from the radial neutron spectra. Region Ia corresponds to the austenite deformation; Region Ib is related to the austenite preferred precipitation; Region II is likely due to the austenite preferred precipitation/growth.

stronger and the (200) peak becomes weaker in the radial direction (Fig. 8(b)). These changes result from the compressive deformation of pre-existing austenite, which is consistent with our previous observation of the change in austenite neutron diffraction peaks for a $2.0 \mathrm{Mn}-0.2 \mathrm{C}$ steel before and after $25 \%$ compression in the austenite single phase region (at $720^{\circ} \mathrm{C}$ ). ${ }^{25}$ )

During the approach to the maximum external stress ( $\sim 0.07<\varepsilon<\sim 0.13$, Region $\mathrm{Ib})$, the integrated intensity of the austenite (111) peak increases together with the (200) and (220) integrated intensities in the axial direction. However, in the radial direction, the austenite (111) peak becomes weaker while the (200) peak becomes stronger.

When the compressive strain exceeds 0.13 (Region II), the integrated intensity of the austenite (111) peak continues to increase and those of the (200) and (220) peaks decrease evidently in the axial direction, but in the radial direction, the integrated intensities of both of (111) and (200) peaks decrease. Region Ib and Region II are speculated to be related to the dynamic precipitation of new austenite particles with preferred orientation and the selective growth of dynamically precipitated austenite, respectively. The austenite orientation color maps of an $\varepsilon=0.6$ warm compressed specimen after $60 \mathrm{~min}$ pre-tempering ${ }^{17)}$ (Fig. 9) show that preferably orientated austenite grains exist locally, as marked by white lines.

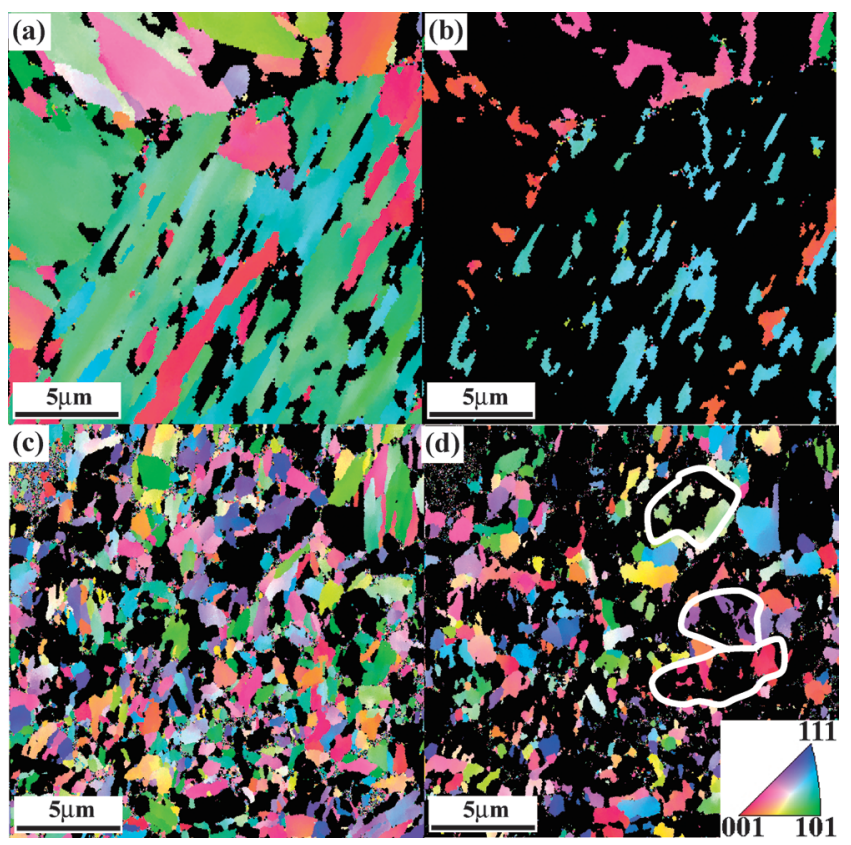

Fig. 9. Crystallographic orientation maps of $60 \mathrm{~min}$ pre-tempered specimens before and after $\varepsilon=0.6$ warm compression (see Ref. 17 for color images): (a) martensite, before compression; (b) austenite, before compression; (c) ferrite, after compression; (d) austenite, after compression.

\subsection{Change in Ferrite Diffraction Spectra during Warm Compression}

Figure 10 compares the ferrite axial diffraction peaks obtained at different loading steps at $500^{\circ} \mathrm{C}$ (see Fig. 5). The (110) lattice plane spacing at $\varepsilon=0.05 \quad\left(d_{110}=\right.$ $0.203425 \pm 0.000007 \mathrm{~nm})$ is smaller than that at $\varepsilon=0.0$ $\left(d_{111}^{0}=0.203780 \pm 0.000007 \mathrm{~nm}\right)$. In other words, the lattice strain of ferrite, $\varepsilon_{110}=\left(d_{110}-d_{110}^{0}\right) / d_{110}^{0}$, is about $-1742 \times$ $10^{-6}$, lower than that of austenite $\varepsilon_{111}$. The $h k l$-specific elastic moduli $E_{h k l}^{\mathrm{K}}$, calculated by the Kröner Modelling Scheme, are 247.9 GPa for the austenite along the [111] direction and $225.5 \mathrm{GPa}$ for the ferrite along the [110] direction, ${ }^{31)}$ respectively. Therefore, the austenite is expected to be subject to a higher average phase stress than the ferrite matrix at the beginning of warm compression, i.e. the preexisting austenite is harder than the ferrite matrix.

In comparison with diffraction peaks obtained at $\varepsilon=0.0$, all $(h k l)$ ferrite peaks show clear peak shifts at $\varepsilon=0.05$ due to the external stress about $329.5 \mathrm{MPa}$. The ferrite (110) peak intensity decreases substantially and the ferrite (211) peak intensity increases a little, which is also consistent with our previous observation on the change in ferrite neutron diffraction peaks for a $2.0 \mathrm{Mn}-0.2 \mathrm{C}$ steel before and after $25 \%$ compression in the ferrite/austenite dual phase region $\left(\right.$ at $\left.640^{\circ} \mathrm{C}\right){ }^{26)}$

When the strain increases to $\varepsilon=0.15$, the ferrite (110) peak intensity decreases slowly but the ferrite (211) and (200) peak intensities decrease significantly. Such change continues to more than $\varepsilon=0.3$. Referring to the microstructure observation, ${ }^{17)}$ this change is related to the dynamic recrystallization of ferrite.

Figure 11 shows the change in integrated intensities of different diffraction peaks with increasing of the compressive strain, obtained by single peak fitting of neutron spec- 

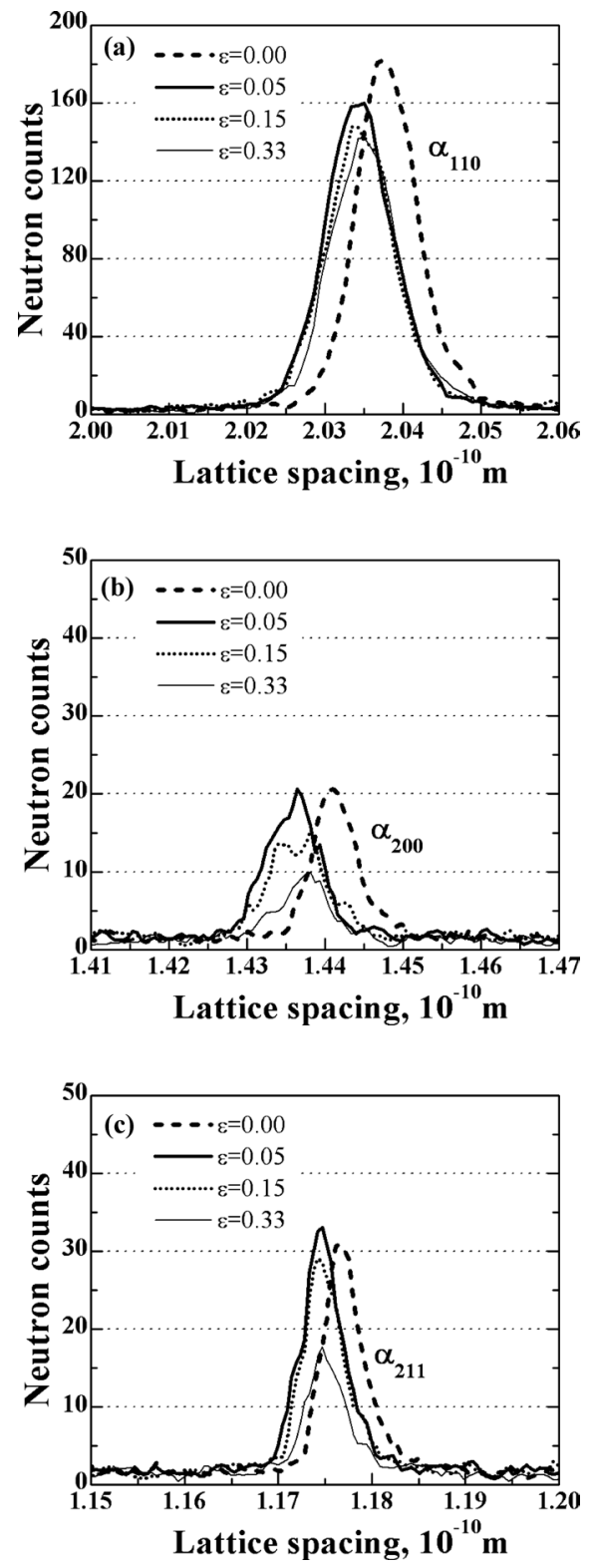

Fig. 10. Comparison of ferrite axial diffraction peaks of the $17 \mathrm{Ni}-0.2 \mathrm{C}$ steel at different compressive strains: (a) ferrite (110) peak; (b) ferrite (200) peak; (c) ferrite (211) peak.

tra measured both in the axial and the radial directions. Before the compressive strain increases to 0.13 , i.e. before the true stress reaches the maximum value, the ferrite (110) integrated intensity obtained in the axial direction decreases rapidly but that obtained in the radial direction decreases slowly. When the compressive strain is beyond $\varepsilon=0.13$, the decrease in ferrite (110) intensity in the axial direction becomes much slower while the decrease in the radial direction accelerates markedly.

For the ferrite (200) and (211) peaks, the integrated intensities obtained in the axial direction increase slowly before $\varepsilon=0.13$ and then decrease evidently beyond $\varepsilon=0.13$, but such data obtained in the radial direction show little change during the warm compression. Based on these changes in ferrite crystallographic orientation, the strain corresponding to the maximum true stress can be regarded as the onset strain of dynamic recrystallization.
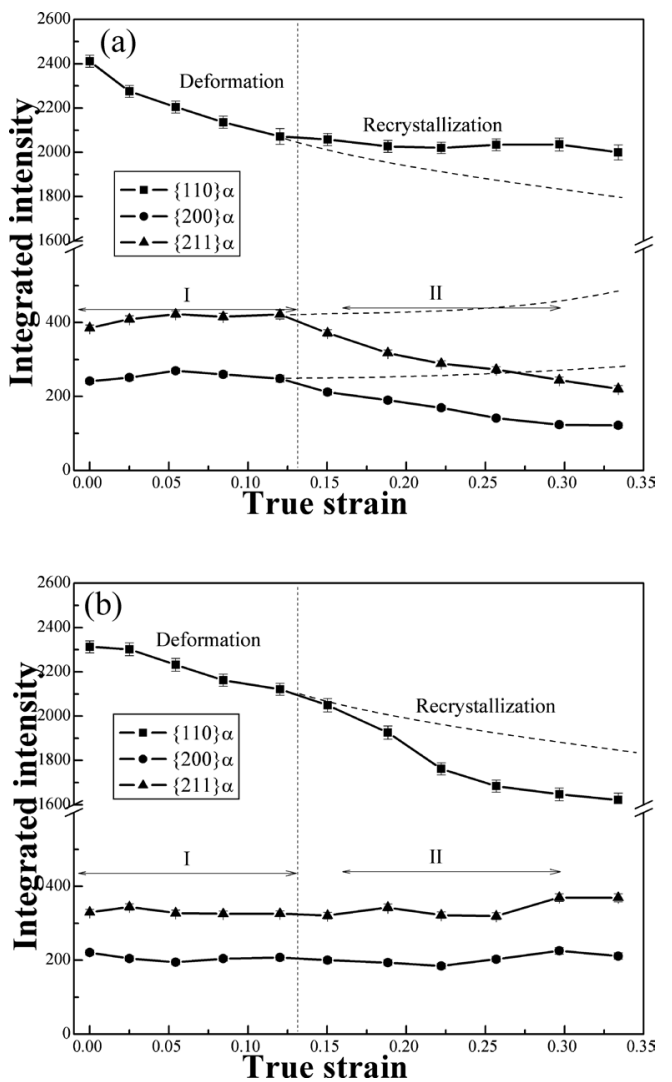

Fig. 11. Change in integrated intensity of ferrite in $17 \mathrm{Ni}-0.2 \mathrm{C}$ steel during warm compression: (a) obtained from the axial neutron spectra; (b) obtained from the radial neutron spectra. Regions I and II correspond to the ferrite deformation and the ferrite dynamic recrystallization, respectively.

\subsection{Effect of the Existence of Austenite Grains on Dy- namic Recrystallization of Ferrite}

Following the dynamic recrystallization, the flow stress decreases gradually to a stable stress. Since both the external loading and the composition change in constituent phases affect the lattice plane spacings, it is difficult to compare the lattice compressive strains directly during warm compression. Considering that the plastic deformation changes the texture as described above, the texture indexes of the two constituent phases can be used to make an indirect comparison between the plastic strains of austenite and ferrite.

According to Bunge's definition, ${ }^{28)}$ the texture index $J$ is a parameter to characterize the sharpness of the texture by the integral of the square of the texture function $f(g)$, without considering the details of the crystallographic orientation distribution:

$$
J=\oint[f(g)]^{2} d g=\sum_{l, \mu, v} \frac{1}{2 l+1}\left|C_{l}^{\mu v}\right|^{2}
$$

where $l, \mu$ and $v$ are the series expansion orders and $C_{l}^{\mu v}$ is the corresponding expansion coefficient. For a random texture, $J=1.0$ and for an ideal texture of single orientation, $J \rightarrow \infty$. Generally, heavier plastic deformation leads to sharper texture. In addition, the TOF neutron spectrum measurement covers a wide range of lattice plane spacings which is partially equivalent to measuring one reflection 

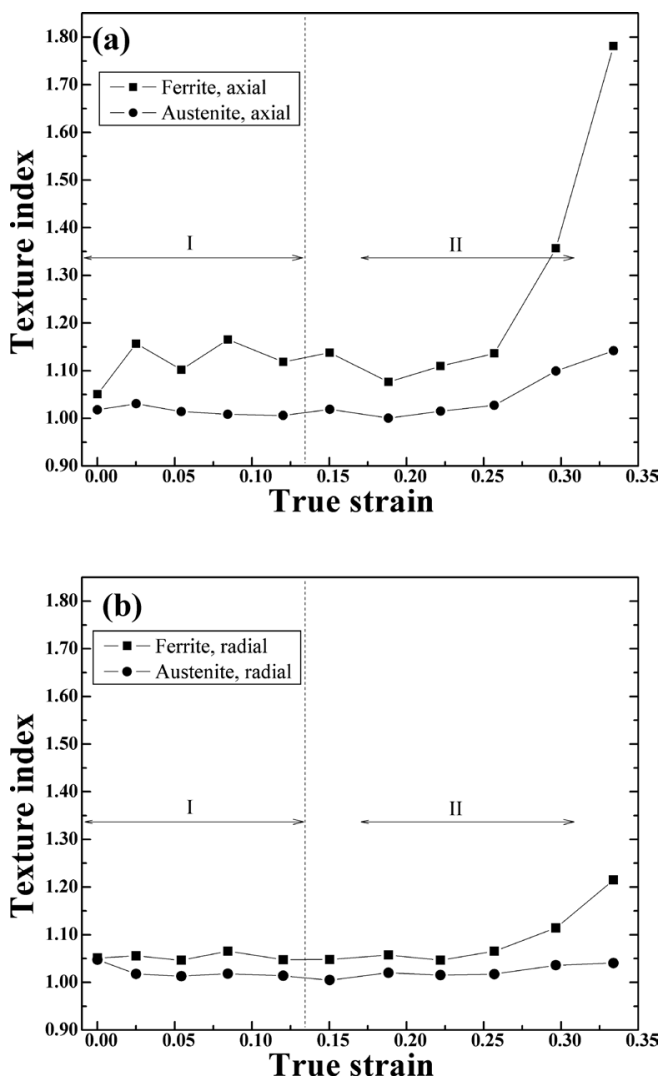

Fig. 12. Change in texture indexes of austenite and ferrite during warm compression: (a) obtained from the axial direction; (b) obtained from the radial direction.

over a wide range of sample orientations. Therefore, the texture indexes calculated from the TOF neutron spectra by the GSAS software package ${ }^{27)}$ can be employed to compare the plastic strains of austenite and ferrite.

As shown in Fig. 12, the texture indexes of the ferrite phase are evidently larger than those of austenite in both the axial and radial directions while the difference between the two directions is related to the details of the crystallographic orientation distribution. This suggests that the plastic deformation occurs preferentially in the ferrite matrix during warm compression.

That is to say, the different peak shifts in Sec. 3.3 reveal that the austenite grains are harder than the ferrite grains. The texture index of the ferrite matrix is larger than that of austenite, suggesting that the plastic deformation occurs preferentially in the ferrite matrix. According to the related recrystallization literature, ${ }^{32)}$ the recrystallized ferrite grains nucleate preferentially in the heterogeneously deformed regions near large hard particles. Therefore, the existence of austenite is believed to accelerate the dynamic recrystallization in the ferrite matrix.

\section{Conclusions}

The austenite precipitation and dynamic recrystallization behaviors of the $17 \mathrm{Ni}-0.2 \mathrm{C}$ martensite steel during isothermal warm compression after isothermal holding at $500^{\circ} \mathrm{C}$ were investigated in situ by the Time-Of-Flight neutron diffraction technique. The main results are as follows:

(1) The neutron diffraction technique can be employed to characterize the microstructure evolution during warm compression, including the austenite precipitation and the dynamic recrystallization.

(2) Warm deformation at $500^{\circ} \mathrm{C}$ was demonstrated to accelerate the austenite precipitation in $17 \mathrm{Ni}-0.2 \mathrm{C}$ martensite steel. Splitting of the austenite (111) peak was found to occur and then disappear during warm compression. The splitting is ascribed to the different carbon concentrations in the dynamically precipitated austenite and the pre-existing austenite, and the disappearance of splitting is related to carbon homogenization at larger strain.

(3) Based on the axial integrated intensities within the neutron spectra, it is found that the ferrite (110) intensity decreases rapidly and the ferrite (200) and (211) intensities increase slowly during warm compression before dynamic recrystallization; the occurrence of dynamic recrystallization leads to an evident deviation from this trend.

(4) The austenite in the $17 \mathrm{Ni}-0.2 \mathrm{C}$ martensite steel after proper pre-tempering is harder than the ferrite matrix at $500^{\circ} \mathrm{C}$. Heterogeneous deformation occurs preferentially in the ferrite, leading to the acceleration of dynamic recrystallization.

\section{Acknowledgement}

The authors thank Dr. R. B. Von Dreele at Argonne National Laboratory, USA for his advice on the texture index analysis. They also thank Mr. J. H. Li at Ibaraki University and Dr. Y. Adachi at National Institute for Materials Science, Japan for their help in the preliminary research. This study was financially supported by the San-hatsu project of the Iron and Steel Institute of Japan and a Grant-in-Aid for Scientific Research (\#IP360325) of the Ministry of Education, Science, Sports and Culture in Japan.

\section{REFERENCES}

1) H. Dong and X. J. Sun: Curr. Opin. Solid State Mater. Sci., 9 (2006), 269.

2) G. Glovre and C. M. Selllers: Metall. Mater. Trans., 4 (1973), 765.

3) T. Maki, S. Okaguchi and I. Tamura: Proc. 6th Int. Conf. on Strength of Metals and Alloys (ICSMA 6), Pergamon Press, New York, (1982), 529.

4) N. Tsuji, Y. Matsubara, Y. Saito and T. Maki: J. Jpn. Inst. Met., 62 (1998), 967.

5) A. Ohmori, S. Torizuka, K. Nagai, N. Koseki and Y. Kogo: Mater. Trans., 45 (2004), 2224.

6) R. L. Miller: Metall. Mater. Trans., 3 (1972), 905.

7) K. Ameyama, N. Matsumura and M. Tokizane: J. Jpn. Soc. Heat Treat., 28 (1988), 233.

8) T. Hayashi, S. Torizuka, T. Mitsui, K. Tsuzaki and K. Nagai: CAMPISIJ, 11 (1998), 1031.

9) Y. Z. Bao, Y. Adachi, Y. Toomine, T. Suzuki, P. G. Xu and Y. Tomota: Tetsu-to-Hagané, 91 (2005), 602.

10) T. Furuhara, T. Yamaguchi, S. Furimoto and T. Maki: Mater. Sci. Forum, 539-543 (2007), 155.

11) N. Tsuji, S. Okuno, Y. Koizumi and Y. Minamino: Mater. Trans., 45 (2004), 2272.

12) N. Tsuchida, Y. Tomota and K. Nagai: Tetsu-to-Hagané, 89 (2003), 1170 .

13) M. Enomoto and E. Furubayashi: Trans. JIM, 18 (1977), 817.

14) M. Moriyama, S. Takaki and N. Kawagoishi: J. Jpn. Soc. Heat Treat., 41 (2001), 266.

15) T. Maki, T. Furuhara and K. Tsuzaki: ISIJ Int., 41 (2001), 571.

16) Narui, K. Morita and Y. Tomota: Proc. Int. Symp. on Ultrafine Grained Steels-2007, ed. by S. Takaki, ISIJ, Japan, (2007), 105.

17) P. G. Xu, J. H. Li, Y. Tomota and Y. Adachi: ISIJ Int., 48 (2008), 1609. 
18) Y. Tomota, T. Suzuki, A. Kanie, Y. Shiota, M. Uno, A. Moriai, N. Minakawa and Y. Morii: Acta Mater., 53 (2005) 463.

19) P. G. Xu, Y. Tomota, P. Lukas, O. Muransky and Y. Adachi: Mater. Sci. Eng. A, A435 (2006), 46.

20) S. G. E. te Velthuis, J. H. Root, J. Sietsma, M. T. Rekveldt and S. van der Zwaag: Acta Mater, 46 (1998), 463.

21) P. G. Xu and Y. Tomota: Acta Metall. Sin., 42 (2006), 681.

22) P. G. Xu and Y. Tomota: Heat Treatment (Shanghai), 21 (2006), No. $4,1$.

23) Y. Tomota and P. G. Xu: Bull. Iron Steel Inst. Jpn., 12 (2007), 15.

24) H. R. Wenk, I. Huensche and L. Kestens: Metall. Mater. Trans. A, 38A (2007), 261.

25) P. G. Xu, Y. Tomota, T. Suzuki, M. Yonemura and E. C. Oliver: CAMP-ISIJ, 21 (2008), 618, CD-ROM.

26) P. G. Xu, Y. Tomota, E. C. Oliver and Y. Adachi: CAMP-ISIJ, 20 (2007), 514.
27) A. C. Larson and R. B. Von Dreele: General Structure Analysis System (GSAS), Los Alamos National Laboratory Report LAUR 86748, (2004), 147.

28) H. J. Bunge: Texture Analysis in Materials Science, Butterworth \& Co., London, (1982), 88.

29) S. C. Chen, Y. Tomota, Y. Shiota, Y. Toomine and T. Kamiyama: Tetsu-to-Hagané, 92 (2006), 557.

30) K. Sawada, T. Ohba, H. Kushima and K. Kimura: Mater. Sci. Eng. A, A394 (2005), 36.

31) M. T. Hutchings, P. J. Withers, T. M. Holden and T. Lorentzen: Introduction to the Characterization of Residual Stress by Neutron Diffraction, Taylor \& Francis, New York, (2005), 230.

32) R. D. Doherty, D. A. Hughes, F. J. Humphreys, J. J. Jonas, D. Juul Jensen, M. E. Kassner, W. E. King, T. R. McNelley, H. J. McQueen and A. D. Rollett: Mater. Sci. Eng. A, A238 (1997), 219. 